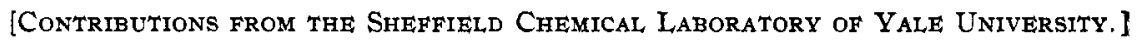

\title{
RESEARCHES ON PYRIMIDINES. LXXIV. SYNTHESIS OF 4-PHENYLCYTOSINE.
}

By Treat B. Johnson and E. Heaton Hemingway.

Received December 16, 1914.

\section{Introduction.}

In a previous publication from this laboratory entitled "The Isomerism. of 4-Phenylisocytosine," Johnson and Hill' have given a description of four isomeric modifications of this aminopyrimidine. Each modification was characterized by its crystalline habit and also by the property of crystallizing in an anhydrous condition. All four isomers, however, combined with hydrochloric acid forming the same monohydrochloride which contained one molecule of water of crystallization. Nothing definite regarding the constitution of these four isomers was contributed. In continuing the study of this question of pyrimidine-isomerism it became of special interest to determine first whether other types of pyrimidines, besides those containing the guanidine grouping, would likewise undergo metameric changes. In other words, is this simply a special case of physical isomerism or a type of pyrimidine-stereoisomerism which theoretically might be expected to occur in other classes of pyrimidines. As a typical representative of another type of aminopyrimidines we, therefore, selected for investigation a urea combination; viz., 4-phenylcytosine (II), whose relationship to 4-phenylisocytosine (I) is apparent by inspection of the two following formulas. Formula I represents a.<smiles>Nc1cccc(N)n1</smiles>

I.<smiles>Nc1cc(N)nc(O)n1</smiles>

II.

guanidine compound while phenylcytosine (II) contains the amidine grouping $\mathrm{H}_{2} \mathrm{~N}-\mathrm{C}=\mathrm{N}-$. A description of the synthesis and properties of this pyrimidine (II) is now given in this paper.

Phenylisocytosine (I) is prepared by the interaction of guanidine carbonate with ethyl benzoylacetate in alcohol solution. Jaeger ${ }^{2}$ and Warmington ${ }^{3}$ independently prepared the pyrimidine in this manner and their observation was confirmed by Johnson and Hill. ${ }^{4}$ The latter also observed that isomeric modifications of this pyrimidine are obtained by condensing guanidine with the $\beta$-ketone ester in the presence of sodium ethylate.

1 This Journal, 36,1202 (I914).

${ }^{2} A n n$., 262, 373 (1890).

3 J. prakt. Chem., [2] 47, 214 (1893).

${ }^{4}$ Loc, cit. 
By the condensation of thiourea with ethylbenzoylacetate, 2-thio-4phenyluracil (III) is easily obtained. Warmington ${ }^{1}$ accomplished this synthesis by heating dry thiourea or ammonium thiocyanate with the $\beta$-ketone ester at $170-180^{\circ}$, and obtained a yield of pyrimidine corresponding to about $30 \%$ of the theoretical. Attempts to bring about this condensation under other conditions were unsuccessful. For example, Warmington" writes as follows: "Weder durch die Einwirkung von Chlorwasserstoffsäure, Bromwasserstoffsäure oder Iodwasserstoffsäure oder von Natriumäthylat bei Gegenwart von Alkohol, noch durch die Verwendung von Eisessig als Losüngsmittel und nachheriges Einleiten von Salzsäuregas der Versetzen mit concentrirter Schwefelsäure in geringer Menge oder mit Essigsäureanhydrid gelang es, Benzoylessigester mit Harnstoff oder Thioharnstoff zu condensiren." On repeating Warmington's work we have not been able to confirm all his conclusions.

We now find that 2-thio-4-phenyluracil (III) can easily be prepared by digesting thiourea with ethyl benzoylacetate in alcohol solution and in the presence of sodium ethylate. In fact, the reaction is so smooth that a yield of the pyrimidine is obtained, which corresponds to over $73 \%$ of the theoretical. There is far less secondary decomposition than when the thiourea is heated directly with the $\beta$-ketone ester as recommended by Warmington.

2-Thio-4-phenyluracil (III) undergoes alkylation smoothly when its sodium salt is digested in alcohol solution with ethyl bromide, giving the corresponding mercaptopyrimidine, namely, 2-ethylmercapto-4-phenyl-6oxypyrimidine $(V)$. The corresponding 2-methylmercapto compound has been described by Wheeler and Merriam. ${ }^{2}$ When digested with hydrochloric acid, mercaptan is evolved and the mercaptopyrimidine (V) is converted quantitatively into 4-phenyluracil ${ }^{3}$ (IV). 4-Phenyluracil is also quantitatively formed by direct desulfurization of 2-thio-4-phenyluracil (III). This is easily accomplished by digestion of the thiopyrimidine with chloroacetic acid.

When 2-ethylmercapto-4-phenyl-6-oxypyrimidine $(V)$ is warmed with phosphorus oxychloride they interact smoothly, forming the halogen derivative 2-ethylmercapto-4-phenyl-6-chloropyrimidine (VI). This chloropyrimidine can be distilled under reduced pressure without decomposition. If heated with strong alcoholic ammonia the halogen is removed and 2ethylmercapto-4-phenyl-6-aminopyrimidine (VII) is the product of the reaction. This aminopyrimidine (VII) undergoes a normal hydrolysis when digested with hydrobromic acid solution, giving ethylmercaptan and the hydrobromic acid salt of 4-phenylcytosine. The yield of this

\footnotetext{
${ }^{1}$ Loc. cit.

${ }^{2}$ Am. Chem. J., 29, 478 (1903).

${ }^{3}$ Warmington, Loc. cit.
} 
salt is nearly quantitative. The free base (II) is easily obtained by decomposing this salt with the required amrount of ammonia or sodium hydroxide. These various transformations are expressed by the following structural formulas:

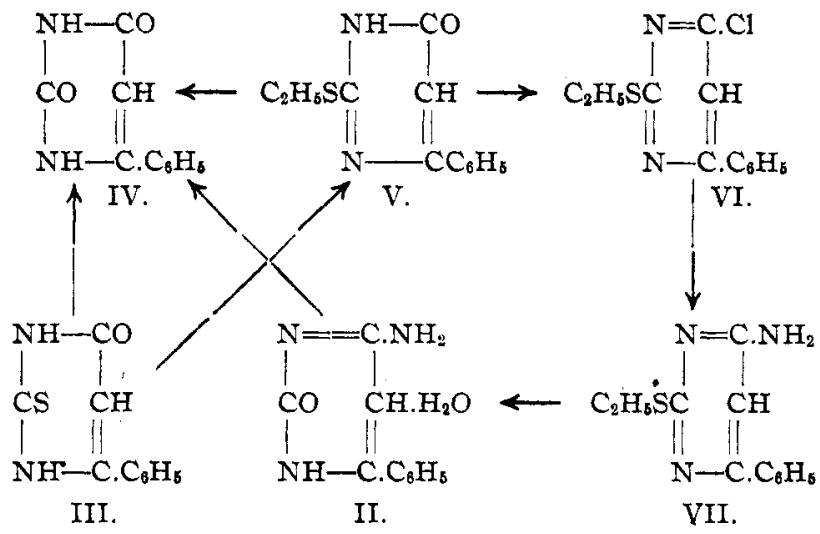

While cytosine ${ }^{1}$ crystallizes with one molecule of water, it is of interest to note that this is not a general property which is characteristic of its carbon-substituted derivatives. In fact, only one of the thirteen carbonsubstitution products, thus far described in papers from this laboratory, has crystallized in a hydrous condition; viz., 5-aminocytosine. ${ }^{2}$ We now find that phenylcytosine is another exception to the rule and likewise crystallizes with one molecule of water. Phenylcytosine is not characterized by such unique physical and chemical properties as was observed in the case of its isomer phenylisocytosine. ${ }^{3}$ It does, however, exist in two distinct modifications. Neither modification possesses any definite melting or decomposition point. They are, however, characterized by their individual crystalline habit. Both modifications are obtained by crystallization from alcohol and also undergo interconversion in the same solvent. The conditions under which these changes are produced are described in the experimental part of this paper. Both modifications combine with hydrochloric and hydrobromic acids respectively, giving the same salts.

\section{Experimental Part.}

The ethylbenzoylacetate, which was used in this work, was prepared according to the directions of Wahl and Doll. ${ }^{4}$

2-Thio-4-Phenyluracil (III).-This pyrimidine can easily be prepared according to the following procedure: Three and three-tenths grams of

${ }^{1}$ Wheeler and Johnson, Am. Chem. J., 29, 492 (1903).

2 Johnson, Johns and Heyl, Ibid., 36, 160 (1906).

8 Johnson and Hill, Loc. cit.

4 Bull. soc. chim., [41] 13, 265 (I913). 
metallic sodium are first dissolved in $45 \mathrm{cc}$. of absolute alcohol and $7 \mathrm{~g}$. of thiourea dissolved in the solution. Thirteen and eight-tenths grams of ethyl benzoylacetate are then added and the mixture digested on the steam bath for several hours (IO-12). The excess of alcohol is then evaporated by heating at $100^{\circ}$ and the sodium salt of phenylthiouracil dissolved in the least possible quantity of cold water. This solution is then cooled and acidified with hydrochloric acid when the pyrimidine will separate in a crystalline condition. The yield obtained was $10.7 \mathrm{~g}$., corresponding to about $73.3 \%$ of the theoretical. It crystallized from acetic acid in needles and melted at $259^{\circ}$.

Desulfurization of 2-Thio-4-phenyluracil by Digestion with Chloroacetic Acid.-Four grams of the thiopyrimidine and $4 \mathrm{~g}$. of chloroacetic acid in $\mathrm{I} 2 \mathrm{cc}$. of water were digested on a sand bath. The thiopyrimidine dissolved and after digesting for 2 hours 4-phenyluracil began to deposit from the hot solution. On cooling, the desulfurized pyrimidine separated completely and was purified by crystallization from alcohol. It deposited as prismatic crystals which melted at $270^{\circ} .1$ The yield was practically quantitative.

2-Ethylmercapto-4-phenyl-6-oxypyrimidine (V).-This mercaptopyrimidine is easily prepared by digesting the sodium salt of 2-thio-4-phenyluracil in alcohol solution with the required amount of ethylbromide. After the reaction is complete the alcohol is then removed by evaporation and the mercaptopyrimidine separated from sodium bromide by trituration with cold water. The pyrimidine is insoluble in this solvent. It can be purified best by crystallization from absolute alcohol. It separates from this solvent in the form of needles which melt at $226^{\circ}$. The compound is insoluble in ether but soluble in benzene. The yield was $78 \%$ of the theoretical. The compound was dried for analysis by heating at $120^{\circ}$. Calculated for $\mathrm{C}_{12} \mathrm{H}_{12} \mathrm{ON}_{2} \mathrm{~S}, \mathrm{~N}=12.06$; found, $\mathrm{N}=\mathrm{I}$ 1.8.

2-Ethylmercapto-4-phenyl-6-chloropyrimidine (VI).-Our method of preparing this halogenated pyrimidine was as follows: Twenty-two and five-tenths grams of the mercaptopyrimidine were placed in a dry flask and the latter connected with a reflux condenser. One hundred cc. of phosphorus oxychloride were then added through the condenser tube and the mixture heated on a steam bath. Hydrochloric acid was copiously evolved and the pyrimidine completely dissolved. After 5 hours' digestion the excess of phosphorus oxychloride was then removed by heating at $40-45^{\circ}$ under diminished pressure and the residue poured into about $300 \mathrm{cc}$. of cold water. After thorough agitation to decompose any phosphorus halides present, the pyrimidine was then extracted with ether. The ether solution was washed with dilute sodium hydroxide solution and finally dried over anhydrous calcium chloride. After removal of the ether

I Wheeler and Merriam, Am. Chem. J., 29, 490 (1903). 
the pyrimidine was then purified by distillation under diminished pressure. It practically all distilled at $232^{\circ}$ at $26.5 \mathrm{~mm}$. pressure and the oil showed no signs of solidifying when cooled to - $10^{\circ}$. The yield of purified product was $19.5 \mathrm{~g}$. or $80.6 \%$ of the theoretical. In a second experiment we used I $3 \mathrm{~g}$. of the mercaptopyrimidine and obtained $9.45 \mathrm{~g}$. of the chloropyrimidine boiling from $235^{-2} 45^{\circ}$ at $30-40 \mathrm{~mm}$. pressure.

Calculated for $\mathrm{C}_{12} \mathrm{H}_{11} \mathrm{~N}_{2} \mathrm{SCl}, \mathrm{N}=\mathrm{II}$.18; found, $\mathrm{N}=\mathrm{I} 1.03$ and Ir.io.

The chloropyrimidine is converted quantitatively into 4-phenyluracil by hydrolysis with hydrochloric acid.

2-Ethylmercapto-4-phenyl-6-aminopyrimidine (VII).-This aminopyrimidine is formed by heating the above chloropyrimidine with strong alcoholic ammonia for two hours at $\mathrm{I}_{3} \mathrm{O}^{-\mathrm{I}} 35^{\circ}$. On opening the bomb tube there was no pressure, but ammonium chloride was suspended in the solution. This was separated by filtration and the solution evaporated at $100^{\circ}$ when the aminopyrimidine was obtained as an oil which solidified on cooling. The yield was $15.5 \mathrm{~g}$. It was further purified by crystallization from $9.5 \%$ alcohol. It crystallized from this solvent in thin plates which melted at $120^{\circ}$ to a clear oil. In a second experiment we obtained $6 \mathrm{~g}$. of pure aminopyrimidine from $9.4 \mathrm{~g}$. of the chloropyrimidine.

Calc. for $\mathrm{C}_{12} \mathrm{H}_{18} \mathrm{~N}_{8} \mathrm{~S}, \mathrm{~N}=18.18$; found, $N=18.01$ and 18.25 .

4-Phenylcytosine (II).-This pyrimidine was obtained in the form of its hydrobromic acid salt by hydrolysis of 2-ethylmercapto-4-phenyl-6aminopyrimidine with hydrobromic acid. Eleven grams of the mercaptopyrimidine were dissolved in $75 \mathrm{cc}$. of hydrobromic acid and the mixture boiled on a sand bath for 6 hours when the evolution of mercaptan had ceased. The hydrobromide separated on cooling. After evaporating the excess of acid the salt was then purified by crystallization from water. It separated in the form of long needles which did not melt below $300^{\circ}$ The salt contained one molecule of water of crystallization which was determined by heating at $110^{\circ}$. Nitrogen determination on anhydrous salt.

Calc. for $\mathrm{C}_{10} \mathrm{H}_{10} \mathrm{ON}_{3} \mathrm{Br} . \mathrm{H}_{2} \mathrm{O}, \mathrm{N}=15.67, \mathrm{H}_{2} \mathrm{O}=6.29$; found, $\mathrm{N}=15.85$ and 15.51, $\mathrm{H}_{2} \mathrm{O}=6.20$.

In order to obtain the free pyrimidine base (4-phenylcytosine) this salt was dissolved in water and the hydrobromic acid neutralized by adding aqueous ammonia solution. The pyrimidine separated at once in a crystalline condition. This base is insoluble in cold ammonia but soluble in sodium hydroxide solution. The pyrimidine dissolved in boiling water and alcohol and crystallized from both solvents in the form of needles arranged in rosets. They did not melt or decompose below $300^{\circ}$. When this base was first prepared (January, 19I4), it was observed to crystallize only in the form of needles. This material was then bottled and not examined further until November, 1914. It had not changed in appearance during this time. On recrystallizing the pyrimidine from alco- 
hol as before we observed, however, a remarkable difference in behavior. The compound dissolved without difficulty in boiling absolute alcohol, but, on cooling, needles did not deposit as previously observed. Instead, the pyrimidine separated in characteristic blocks of rhombohedral habit. If recrystallized from $95 \%$ alcohol a mixture of needles and blocks was obtained in which the blocks predominated. In fact it was almost impossible to obtain needles alone by crystallization from alcohol. The pyrimidine base was synthesized a second time in November, 1914, and purified according to our original method. The base behaved exactly as the original preparation. We could obtain at will, by crystallization from $95 \%$ alcohol, the needle and prism modifications. Although the pyrimidine was purified by crystallization from absolute and $95 \%$ alcohol it still contained one molecule of water of crystallization. So firmly was this bound in the molecule that it could not be expelled by heating at $100^{\circ}$. At $\mathrm{I} 20^{\circ}$ it was removed with difficulty. At the same time the pyrimidine apparently underwent a partial hydrolysis, which accounts for the low analytical values obtained for nitrogen.

Water determination:

Calc. for $\left.\mathrm{C}_{10} \mathrm{H}_{9}\right) \times 3 . \mathrm{H} \cdot \mathrm{O}, \mathrm{HO}=8.7$; found, $\mathrm{H}_{2} \mathrm{O}=8.3 \mathrm{I}$.

Nitrogen determinations in the anl.ydrous base:

Calc. for $\mathrm{C}_{10} \mathrm{H}_{8} \mathrm{ON}_{3}, \mathrm{~N}=22.4$; found, $\mathrm{N}=22 . \mathrm{I}, 2 \mathrm{I} .9 \mathrm{I}$ and $2 \mathrm{I} .95$.

Hydrochloride, $\mathrm{C}_{10} \mathrm{H}_{9} \mathrm{ON}_{3} \cdot \mathrm{HCl} \cdot \mathrm{H}_{2} \mathrm{O}$. - This salt is easily obtained by dissolving the pyrimidine base in dilute hydrochloric acid and then allowing the solution to crystallize. It separated in the form of long, colorless needles which melted at $274^{\circ}$ with decomposition. The salt was dried for analysis over concentrated sulfuric acid.

Calc. for $\mathrm{C}_{10} \mathrm{H}_{8} \mathrm{ON}_{3} \cdot \mathrm{HClH}_{2} \mathrm{O}, \mathrm{N}=17.44 ;$ found, $\mathrm{N}=17.58$ and 17.49 .

The nitrate of 4-phenylcytosine is characterized by its property of crystallizing from water in two distinct forms. When it deposits from a hot, saturated aqueous solution it first separates in the form of needles. This form, however, is not permanent and as the solution cools the needles disappear and are replaced by characteristic prismatic crystals. The salt decomposes when heated above $245^{\circ}$.

NEW HAVEN, ConN.

[Contributions from the Sheffield Chemical Laboratory OF Yale University.]

RESEARCHES ON HYDANTOINS. XXX. STEREOISOMERIC MODIFICATIONS OF BENZALHYDANTOIN.

By Treat B. Johnson and Joseph $S$. Bates.

Received December 16, 1914.

Benzalhydantoin (II) was first prepared by Ruhemann and Cunnington ${ }^{1}$ by heating ethyl phenylpropiolate with urea in alcohol solution and in the

1 J. Chem. Soc., 75, 958 (1899). 